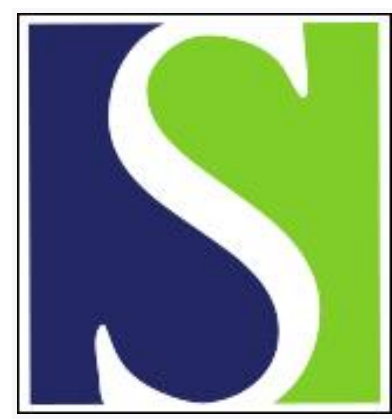

Scand J Work Environ Health 1984;10(4):229-234

https://doi.org/10.5271/sjweh.2337

Issue date: Aug 1984

Effect on the uptake kinetics of serotonin (5-hydroxytryptamine) in platelets from workers with long-term exposure to organic solvents. A pilot study. by Beving $\mathrm{H}$, Kristensson J, Malmgren R, Olsson P, Unge $\mathrm{G}$

This article in PubMed: www.ncbi.nlm.nih.gov/pubmed/6494842

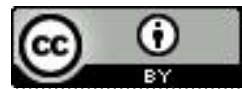




\title{
Effect on the uptake kinetics of serotonin (5-hydroxytryptamine) in platelets from workers with long-term exposure to organic solvents
}

\section{A pilot study}

\author{
by Håkan Beving, PhD, ${ }^{1}$ Jan Kristensson, BSc, ${ }^{3}$ Rigmor Malmgren, DrMedSc, ${ }^{1}$ Per Olsson, MD, ${ }^{1}$ \\ Gunnar Unge, $M D^{2}$
}

\begin{abstract}
BEVING H, KRISTENSSON J, MALMGREN R, OLSSON P, UNGE G. Effect on the uptake kinetics of serotonin (5-hydroxytryptamine) in platelets from workers with long-term exposure to organic solvents. Scand J Work Environ Health 10 (1984) 229-234. Six workers from a paint industry were examined concerning the concentration of solvents in the breathing zone, the platelet count and kinetic uptake of serotonin [5-hydroxytryptamine (5-HT)], the serum concentration of calcium, potassium and sodium, and $\mathrm{pH}$. The degree of exposure was found to be moderate. The results showed a decrease in platelet count in whole blood and platelet-rich plasma. The maximum uptake rate for serotonin in platelets $\left(\mathrm{V}_{\mathrm{max}}\right)$ was significantly increased compared to that of nonexposed subjects. No changes in the ionic concentration and $\mathrm{pH}$ of serum were observed. One worker was reexamined after a six-week period of nonexposure. Though the measured platelet variables were still aberrant, the values approached normal.
\end{abstract}

Key terms: plasma, metal ions, serum.

The platelet is accepted as an appropriate model cell for the presynaptic neuron $(18,26,27)$. A technique for the kinetic determination of the uptake of serotonin [5-hydroxytryptamine (5-HT)] in human platelets has recently been developed (11). By this method the platelet 5-HT uptake is measured in fresh platelet-rich plasma, prepared from whole blood by low-speed centrifugation. Using this method, we have been able to detect 5-HT uptake changes in platelets from patients with suspected 5-HT related maladies such as endogenous asthma, endogenous depression, and migraine headaches $(12,13,14,15)$.

We have earlier demonstrated that the platelets of car spray painters, who had been exposed to a mixture of organic solvents and isocyanates in a work environment which was considered to be adequately ventilated, exhibited abnormal serotonin (5-HT) uptake kinetics (1). It is well known that organic solvents and their metabolites affect the neuronal membrane $(17,22,23,24)$. A similar influence on the platelet membrane of solvents and/or their metabo-

1 Department of Experimental Surgery, Thoracic Clinics, Karolinska Hospital, Stockholm, Sweden.

2 Department of Thoracic Medicine, Karolinska Hospital, Stockholm, Sweden.

3 Department of Analyticar Chemistry, University of Stockholm, Stockholm, Sweden.

Reprint requests to: Professor P Olsson, Department of Experimental Surgery, Thoracic Clinics, Karolinska Hospital, S-104 01 Stockholm, Sweden. lites might therefore be possible and might be one of the explanations for aberrant 5-HT uptake kinetics. The present investigation was designed to determine whether humans exposed mainly to organic solvents also exhibit a decrease in platelet count and a rise in 5-HT uptake capacity $\left(\mathrm{V}_{\max }\right)$ in platelets.

Interactions of different metal ions with the serotonin uptake system in platelets have been reported (7). In an investigation of whether the exposed subjects had any detectable changes in their electrolyte composition in serum, measurements of calcium, potassium, and sodium were performed. Thus measurements of solvent exposure, platelet count, 5-HT uptake kinetics, and metal ion concentration in serum were included.

\section{Subjects and methods}

\section{Blood donors}

The test subjects were six men, ages between 34 and 58 years, employed in a graphic paint manufacturing plant. All of them had been continuously exposed to solvents for several years in their work environment. The reference material consisted of 32 women and 18 men, age range 25 to 56 years, both smokers and nonsmokers, but not exposed to volatile solvents in their occupational environment. These volunteers participated in a current investigation concerning the platelet 5-HT uptake in a healthy population. No differ- 
ences between the sexes could be observed regarding platelet counts and kinetic parameters of the 5-HT transport (11).

No intake of any kind of drug was permitted for $10 \mathrm{~d}$ prior to the blood sampling, either for the test subjects or for the referents.

\section{Solvent exposure determination}

New methods for sampling solvent vapors from the breathing zone have been developed (8). In the method used in this study samples from the inhaled vapors were collected with the aid of portable diffusion samplers carried by the investigated subjects for $8 \mathrm{~h}$. The solvent composition was then automatically analyzed by a gas chromatograph coupled to a thermal device, which was first connected to the sampler (9).

Exposure measurements were made with the aid of the ATD-50 system (Automatic Thermal Desorption, Perkin-Elmer, Ltd, England). The diffusion sampler consists of a stainless steel tube $(90 \times 5 \mathrm{~mm}$, inner diameter). A stainless steel gauze at one end limits the diffusion zone length to $15 \mathrm{~mm}$. The sampler was packed with Tenax GG 80/60 mesh (21), which was fixed in the tube by gauze and a spring (figure 1). Exposure measurement during $8 \mathrm{~h}$ was made for each worker the day before the blood sampling and biological examination. Collection of the air-solvent mixture was made in the breathing zone. On sampling, the storage cap was exchanged for the diffusion cap. After the sampling period, the samplers were loaded into the automatic desorption device connected to a gas chromatograph (Sigma 2B, Perkin-Elmer) equipped with a flame ionization detector and a peak area integrator. A fused silica capillary column $(25 \mathrm{~m} \times 0.3 \mathrm{~mm})$ with a bonded phase of CPW Wax 57 (Chrompak, The Netherlands) was used in the instrument as previously described (9.). Calibration of the system was achieved by the injection of known concentrations of toluene and ethyl acetate (analytical grades) into fresh diffusion samplers. Unidentified compounds in the gas chromatograph and the sum of solvents in the gas mixture were calculated as parts per million of toluene. In one case additional calibration solvents were applied. Only substances with boiling points below $200^{\circ} \mathrm{C}$ were detected. Full details of the assay system have been published elsewhere (5).

\section{Determination of platelet serotonin uptake kinetics}

The experiments were performed between 45 and 60 min after the blood sampling, as previously described in detail (11). Platelet-rich plasma was prepared from the blood samples, mixed with one-tenth of an ACD solution (citric acid $1.37 \mathrm{~g}$, sodium citrate $2.5 \mathrm{~g}$, an-

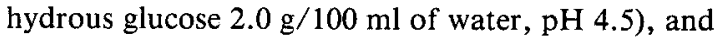
the uptake of ${ }^{14} \mathrm{C}$-labeled 5-HT creatinine sulfate (final concentration from 1.0 to $2.0 \mu \mathrm{M}$ ) was measured during $60 \mathrm{~s}$. The platelet count, in whole blood and platelet-rich plasma, was determined by electronic cell counting (Linson 431A, LIC Instrument, Solna, Sweden). Hematocrit was determined by highspeed centrifugation (Wifug, Stockholm, Sweden).

Adaptation of the kinetic data to MichaelisMenten's simple saturation kinetics was ascertained by linearization of the saturation curve according to Scatchard. Statistically significant linearity was present [correlation coefficient $(r) \leq-0.64)$ ]. In order to obtain a mathematical appraisal of the homogeneity of the 5-HT uptake, the Sips' distribution equation was applied to the Scatchard plot. The kinetic parameters $\mathrm{K}_{\mathrm{m}}(\mu \mathrm{mol} / \mathrm{l})$ and $\mathrm{V}_{\max }\left(\mathrm{pmol} \cdot 10^{6}\right.$ platelets $\cdot \min ^{-1}$ ) were calculated according to LineweaverBurk. The details of the mathematical processing of the data have been described previously $(11,20)$.

Ninety-five percent tolerance intervals for the values of the Scatchard correlation coefficient $[\mathrm{r}(\mathrm{S})]$, the index of heterogeneity in the Sips analysis $(\alpha)$, and $K_{m}$ and $V_{\max }$ were calculated for the 5-HT uptake in platelets from the 50 referents. Since the tolerance interval covers a certain section of a population $(95 \%)$, values falling outside the limits of the intervals were considered to be significantly abnormal.

\section{Ionic concentration and $p H$ determination}

The ionic concentrations of potassium, sodium, and calcium in the test platelet-rich plasma and serum were determined with an ion selective analyzer (Microlyte, Kone Instruments, Espoo, Finland); pH in these media was determined with the aid of PHM

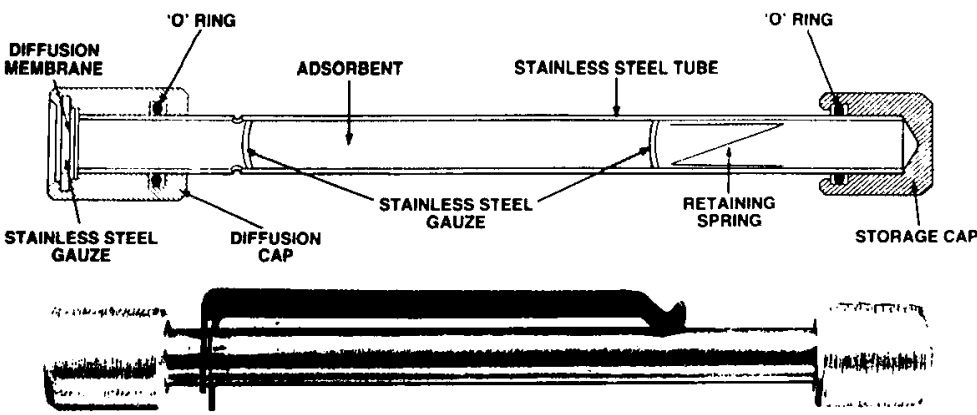

Figure 1. ATD 50 sampling tube, length $10 \mathrm{~cm}$. 
82 pH-meter (Radiometer 143: 690 167, Denmark), furnished with a combined glass electrode, (Radiometer, GK 2321, Denmark).

\section{Results}

Gas chromatography of the solvents desorbed from the samplers revealed that all of the exposed subjects had been exposed to ethyl acetate and toluene although in concentrations below the Swedish hygienic standards (figure 2). In all the samples, primarily unidentified substances were present in concentrations varying between 3 and $11 \mathrm{ppm}$ (table 1).

In the case of the sampler with the largest fraction of primarily unidentified substances, the solvent mixture was further analyzed and was found to consist of pseudocumene (1,2,4-trimethyl-benzene), cyclohexanone, mesitylene (1,3,5-trimethyl-benzene), 1,2,3-trimethyl-benzene, and n-propylbenzene.

Table 1. Concentration of identified and unidentified organic solvents in the breathing zone.

\begin{tabular}{ccccc}
\hline Subject & $\begin{array}{c}\text { Toluene } \\
\text { (ppm) }\end{array}$ & $\begin{array}{c}\text { Ethyl } \\
\text { acetate } \\
\text { (ppm) }\end{array}$ & $\begin{array}{c}\text { Unidentified } \\
\text { substances } \\
\text { (ppm of } \\
\text { toluene) }\end{array}$ & $\begin{array}{c}\text { Total } \\
\text { exposure }\end{array}$ \\
\hline 1 & 2 & 0 & 11 & 13 \\
2 & 68 & 0 & 6 & 74 \\
3 & 16 & 0 & 4 & 20 \\
4 & 9 & 34 & 5 & 53 \\
5 & 25 & 78 & 3 & 111 \\
6 & 7 & 0 & 7 & 14 \\
\hline
\end{tabular}

Hygienic

standard $(8 \mathrm{~h}) \quad 80 \quad 200$

a The concentration of unidentified organic substances and total exposure has been estimated as parts per million of toluene, ie, the adsorbtion and response for toluene have been used.
Although the hematocrit values showed a normal variation for the test subjects and did not differ from those of the reference group, the platelet count was, both in whole blood and in platelet-rich plasma, on the average markedly lower than that in the reference material, and in 4 out of 12 determinations it was below the $95 \%$ tolerance limit (table 2).

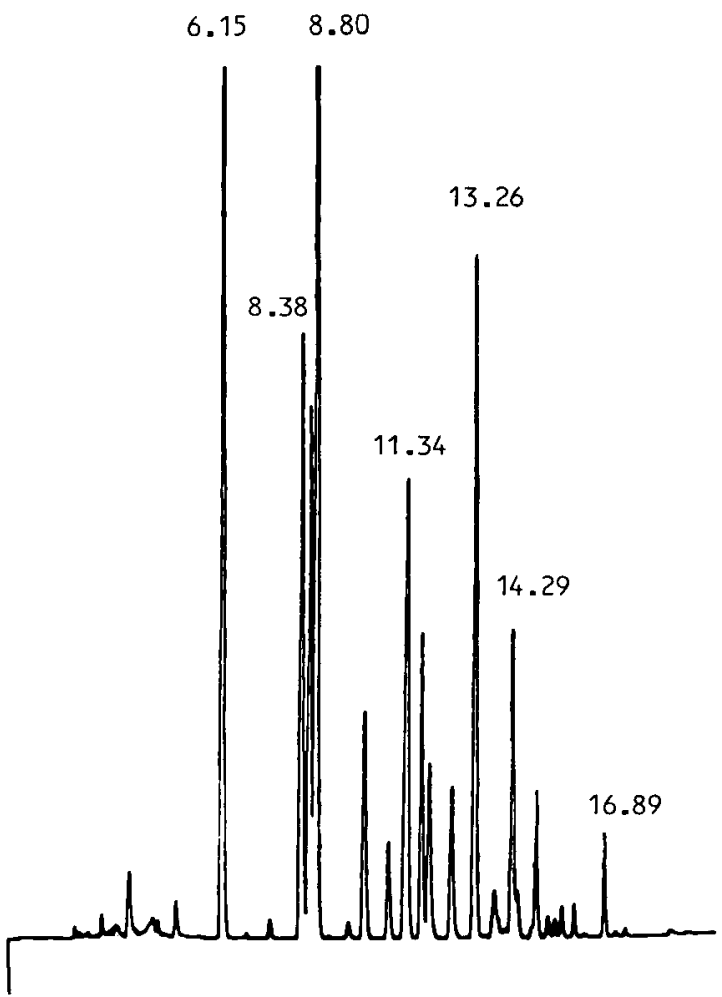

Figure 2. Example of chromatogram from diffusive sample taken at a printing plant.

Table 2. Platelet count in whole blood and platelet-rich plasma and the following kinetic parameters: the correlation coefficient in the Scatchard analysis [r(S)], the index of heterogeneity according to Sips $(\alpha)$, the concentration of serotonin. needed to achieve half the maximum uptake rate $\left[K_{\mathrm{m}}(\mathrm{mmol} / \mathrm{l})\right]$, and the maximum uptake rate when the carrier is saturated $\left[\mathrm{V}_{\max }\left(\mathrm{pmol} \cdot 10^{-6}\right.\right.$ platelets $\left.\left.\cdot \mathrm{min}^{-1}\right)\right]$ for six solvent-exposed workers, as well as the $95 \%$ tolerance interval for the 50 referents.

\begin{tabular}{|c|c|c|c|c|c|c|}
\hline \multirow{2}{*}{$\begin{array}{l}\text { Case } \\
\text { number }\end{array}$} & \multicolumn{2}{|c|}{ Platelets $\times 10^{-9} / 1$} & \multicolumn{4}{|c|}{ Kinetic parameters } \\
\hline & Blood & $\begin{array}{l}\text { Platelet-rich } \\
\text { plasma }\end{array}$ & $r(S)$ & $\alpha$ & $\mathrm{K}_{\mathrm{m}}$ & $\mathrm{V}_{\max }$ \\
\hline $\begin{array}{l}1 \\
2 \\
3 \\
4 \\
5 \\
6 \\
3^{b}\end{array}$ & $\begin{array}{c}133 \\
171 \\
82^{\mathrm{a}} \\
144 \\
193 \\
92^{\mathrm{a}} \\
104^{\mathrm{a}}\end{array}$ & $\begin{array}{l}187^{a} \\
269 \\
189^{a} \\
298 \\
365 \\
223 \\
213\end{array}$ & $\begin{array}{l}-0.92 \\
-0.96 \\
-0.96 \\
-0.97 \\
-0.94 \\
-0.90 \\
-0.89\end{array}$ & $\begin{array}{l}0.98 \\
0.98 \\
0.97 \\
0.98 \\
0.95 \\
0.97 \\
0.96\end{array}$ & $\begin{array}{l}1.05 \\
0.99 \\
0.92 \\
1.07 \\
0.79 \\
1.39 \\
1.03\end{array}$ & $\begin{array}{l}2.81^{\mathrm{a}} \\
2.31 \\
3.25^{\mathrm{a}} \\
2.36 \\
1.57 \\
4.47^{\mathrm{a}} \\
3.10^{\mathrm{a}}\end{array}$ \\
\hline $\begin{array}{l}\text { Mean (numbers 1-6) } \\
\text { SD }\end{array}$ & $\begin{array}{r}136 \\
39\end{array}$ & $\begin{array}{r}225 \\
63\end{array}$ & $\begin{array}{r}-0.95 \\
0.02\end{array}$ & $\begin{array}{l}0.973 \\
0.009\end{array}$ & $\begin{array}{l}1.04 \\
0.18\end{array}$ & $\begin{array}{l}2.79 \\
0.91\end{array}$ \\
\hline $\begin{array}{l}\text { Mean } \\
95 \% \text { tolerance inter- } \\
\text { val for the referents } \\
(N=50)-\text { lower } \\
\text { and upper limits }\end{array}$ & $118-332$ & $206-696$ & $-0.78--0.97$ & $0.904-1.002$ & $0.44-1.96$ & $0.52-2.42$ \\
\hline
\end{tabular}

a Values outside the $95 \%$ tolerance interval.

b Reexamination after a nonexposure time of six weeks. 
Table 3. Potassium $\left(\mathrm{K}^{+}\right)$, sodium $\left(\mathrm{Na}^{+}\right)$, and calcium $\left(\mathrm{Ca}^{++}\right)$ ionic concentrations $(\mathrm{mmol} / \mathrm{l})$ and $\mathrm{pH}$ values of serum from six solvent-exposed workers and six referents.

\begin{tabular}{lrlrrr}
\hline & \multicolumn{2}{c}{ Exposed } & & \multicolumn{2}{c}{ Referents } \\
\cline { 2 - 3 } \cline { 5 - 6 } & Mean & SD & & Mean & SD \\
\cline { 2 - 5 } $\mathrm{K}^{+}$ & 4.8 & 0.5 & & 4.5 & 0.4 \\
$\mathrm{Na}^{+}$ & 145.4 & 2.1 & & 141.6 & 3.6 \\
$\mathrm{Ca}^{+}+$ & 1.1 & 0 & & 1.1 & 0 \\
$\mathrm{pH}$ & 8.0 & 0.1 & & 7.9 & 0.1 \\
\hline
\end{tabular}

Table 4. Potassium $\left(\mathrm{K}^{+}\right)$, sodium $\left(\mathrm{Na}^{+}\right)$, and calcium $\left(\mathrm{Ca}{ }^{++}\right)$ ionic concentrations $(\mathrm{mmol} / \mathrm{l})$ and $\mathrm{pH}$ values of platelet-rich plasma (PRP) $\left(0.04 \mathrm{ml}\right.$ of ACD solution ${ }^{2} / \mathrm{ml}$ of blood) from six solvent-exposed workers and seven referents.

\begin{tabular}{lrlrrr}
\hline & \multicolumn{2}{c}{ Exposed } & & \multicolumn{2}{c}{ Referents } \\
\cline { 2 - 3 } \cline { 5 - 6 } & Mean & SD & & Mean & SD \\
\cline { 2 - 3 } $\mathrm{K}^{+}$ & 4.0 & 0.3 & & 3.8 & 0.2 \\
$\mathrm{Na}^{++}$ & 141.6 & 2.5 & & 139.6 & 2.8 \\
$\mathrm{Ca}^{++}$ & 0.1 & 0 & & 0.1 & 0 \\
$\mathrm{pH}$ & 8.0 & 0.1 & & 7.6 & 0.1 \\
\hline
\end{tabular}

a $\mathrm{ACD}=1.37 \mathrm{~g}$ of citric acid, $2.5 \mathrm{~g}$ of sodium citrate, and $2.0 \mathrm{~g}$ of anhydrous glucose $/ 100 \mathrm{ml}$ of water, $\mathrm{pH} 4.5$ ).

The 5-HT uptake by the platelets from the exposed workers adhered in all respects to a saturable mode of transport, as can be expected from the high coefficients in the Scatchard and Sips analyses. These values always fell within the tolerance interval for normality (table 2). Since the 5-HT transport obeyed Michaelis-Menten's kinetics, $\mathrm{K}_{\mathrm{m}}$ and $\mathrm{V}_{\max }$ could be derived. The $\mathrm{K}_{\mathrm{m}}$ value in all cases fell within the normal tolerance interval, although on an average in the test group it seemed to be slightly lower than in the reference group. The $\mathrm{V}_{\max }$ value was, however, above the normal $95 \%$ tolerance limit for three of the six men in the exposed group, and the mean value of this group was close to double that of the reference value (table 2). $\mathrm{V}_{\max }$ was inversely proportional to the platelet count both in whole blood $(r=-0.89)$ and in platelet-rich plasma $(\mathrm{r}=-0.71)$.

According to our experience, 5-HT uptake kinetics in platelets are dependent on ionic concentration and $\mathrm{pH}$ in the test plasma. It was therefore deemed worthwhile to determine the $\mathrm{pH}$ and ionic concentrations of potassium, sodium, and calcium in the test plasma and serum from the exposed subjects and in six age-matched male nonexposed volunteers. For none of these parameters could any difference be found between the two groups (tables $3 \& 4$ ).

One of the solvent-exposed subjects (number 3 ) who, due to a thumb fracture, had not been exposed (to his occupational environment) for six weeks, was reexamined before returning to work. After the nonexposed period, only minor changes had occurred in the previously measured parameters. However, the platelet count in whole blood and platelet-rich plasma showed a tendency to increase; the $\mathrm{K}_{\mathrm{m}}$ and $\mathrm{V}_{\max }$ for the 5-HT uptake in the platelets increased and decreased, respectively (table 2 ).

\section{Discussion}

Two main requirements have to be fulfilled when the impact of environmental volatile substances on the human organism is to be studied. The first is that possible toxic agents in the breathing atmosphere must be characterized and quantified. The second is that a sensitive biological test should be found that can reveal functional disturbances in the organism.

The first requirement was accomplished in the present investigation with the aid of the ATD 50 system. This technique highly facilitates the sampling of the gas mixture in the breathing zone, since the organic solvent is transported into the absorbent of the sampler by diffusion according to Fick's first law of diffusion. Pumps for gas collection are not required. The system was designed for automatic thermal desorption of the absorbed solvents, and analyses of 50 samples at a time could be performed with high precision.

Concerning the question of whether the 5-HT transport in the platelet is a relevant biological parameter for detecting the influence of inhaled organic solvents on the organism, it can first be stated that the assay used in the present investigation is performed on living cells in an almost native environment. The assay also discriminates to what extent the 5-HT is taken up by the platelet by passive diffusion and by a saturable transport mechanism. Provided the latter mechanism is dominant, the uptake capacity can be quantified (11) from the derived $K_{m}$ and $V_{\max }$ values. Furthermore, the platelet is generally accepted as a model cell for the serotonergic presynaptic neuron $(18,26,27)$, the function of which is inaccessible for direct studies in humans. Distinct abnormalities of the 5-HT transport in platelets from patients with endogenous depression have accordingly been demonstrated (12). Another kind of specific platelet 5-HT transport aberration occurs in patients having migraine headaches and endogenous asthma $(13,14,15)$. Characterization and quantification of the 5-HT transport in platelets thus seem to provide possibilities to describe a biological event, the altered function of which might be connected with disease.

The workers in this particular plant were expected to be exposed to toluene and ethyl acetate, solvents which were thus the reference substances of first choice. The breathing air for all the workers was also shown to contain toluene and ethyl acetate, although in concentrations below accepted limits (16). The concentration of other solvents was low, and the extended analysis in one case revealed that this fraction could consist of a variety of organic compounds. We consider the total exposure to identified and unidentified solvents to be moderate with regard to the work environment in question.

It is quite clear that the platelets of the workers were affected as compared to those of the large number of reference subjects, although no correlation between the concentration of the inhaled solvents and 
degree of platelet alterations was obvious (see tables 1 \& 2). The platelet count was equally reduced by almost $50 \%$ in whole blood and in the platelet-rich plasma derived from the whole blood. The fact that two out of six determinations resulted in significantly lowered platelet counts indicates that the platelet distribution of the platelet counts in the solventexposed group was shifted towards lower values. The mode of the 5-HT transport by the platelets in the test group was similar to that of the reference material, ie, a saturable uptake mechanism was working without a measurable addition of passive 5-HT diffusion through the platelet membrane (11). The results are in accordance with those data obtained in our previous investigation on car spray painters, who were exposed to both organic solvents and isocyanates. $V_{\max }$ and platelet count are negatively correlated in healthy nonexposed volunteers (Malmgren et al, unpublished results). An increase in $\mathrm{V}_{\max }$ could be the result of a compensation for a reduction in circulating platelets. The latter might in turn indicate an increased peripheral destruction of platelets.

The cause of the lowered number of circulating platelets in the solvent-exposed workers and the mechanism behind the altered 5-HT transport capacity are far from clear. The reduced platelet count may on one hand be due to an impact of the organic solvents on platelet generating cells in the bone marrow $(2,3,4,10,19,22,23)$. It is, however, difficult to conceive that the platelets from an impaired generating mechanism should have an increased, energyrequiring 5-HT transport capacity. An increased ratio of $\mathrm{Na}^{+}-\mathrm{K}^{+}$and/or a slight decrease in the $\mathrm{pH}$ of the test platelet-rich plasma induce an enhancement of $\mathrm{V}_{\text {max }}$. In these workers, however, there were no changes in these electrolytes or $\mathrm{Ca}^{++}$, and no signs of acidosis in the platelet-rich plasma (25). On the other hand, the reduced platelet count in the blood could have been due to an abnormal destruction of platelets, ie, the survival time of the platelet is shortened. Newly released platelets are heavier and larger than older ones, and they have a higher metabolic activity and an increased capacity to take up 5 -HT $(2,6)$. Thus, provided organic solvents enhance platelet turnover by some mechanism, both the decrease in the number and in the elevated transport capacity might be explained. The fact that $V_{\text {max }}$ in the present investigation increased with decreasing platelet counts supports this latter explanation for the observed changes.

The increased $V_{\max }$ implies that platelets from solvent-exposed workers have an increased capacity to take up 5-HT. However, the pathophysiological implication of this phenomenon is obscure. Changes in the platelet 5-HT uptake might mirror similar changes in the central nervous system.

The results from the reexamination of the worker who had been unexposed to solvents for six weeks, during which period at least five new platelet genera- tions would have passed (2), may be of some significance. The measured platelet variables were still aberrent and the breathing capacity still impaired. All values, approached normal however. The small but consistent tendency towards normalization during the unexposed period indicates that the abnormalities observed in the present investigation are related to exposure to organic solvents but also that these substances have more than an acute impact on the human organism.

Whether platelets from exposed subjects (i) are affected by the inhaled solvents directly in the lung, (ii) have a changed regeneration time, or (iii) have an altered size and thus changed metabolic activity (due to an increased release from the bone marrow) is still unclear.

\section{Acknowledgments}

This work was supported by grants from the Swedish Work Environment Fund, project no 82-0534, the Swedish Medical Research Council, project no 5962, and the Swedish National Association against Heart and Lung Diseases.

\section{References}

1. Beving $H$, Malmgren $R$, Olsson $P$, Tornling $G$, Unge $G$. Increased uptake of serotonin in platelets from car painters occupationally exposed to mixtures of solvents and organic isocyanates. Scand J Work Environ Health 9 (1983) 253-258.

2. Bloom A-L, Thomas $\mathbf{P}$, ed. Haemostasis and thrombosis. Churchill Livingstone, Edinbourgh 1981.

3. Gerade HW. Toxicology and biochemistry of aromatic hydrocarbons. In: Browning E, ed. Elsevier monographs in toxic agents. Elsevier, Amsterdam 1960, p 73.

4. Heidemann E. Humorale Regulatoren der Zellproliferation in der Hämatopoese: II Erythropoese, Megakaryopoese, pluripotente Stammzelle. Klin Wochenschr 58 (1980) 1167.

5. Hurell RA. An automated system for the thermal desorption of personal diffusion samplers. Int Environ Saf June (1981) 281-290.

6. Karpatin S. Heterogeneity of human platelets: Metabolic and kinetic evidence suggestive of young and old platelets. Ser Haematol 4 (1975) 75-97.

7. Komulainen $\mathbf{H}$, Tuomisto J. Effects of heavy metals on monoamine uptake and release in brain synaptosomes and blood platelets. Neurobehav Toxicol Teratology 4 (1982) 647-649.

8. Kristensson J. The use of ATD-50 system with fused silica capillaries in dynamic headspace analysis. In: Schreier P, ed. Analysis of volatiles: New methods and their applications: Proceedings International Workshop University Würzburg, Sept 28-30, 1983. Walter de Gruyter \& Co, Berlin 1984, p 109-120.

9. Kristensson J, Sjölund N. The use of fused silica columns in the ATD 50 system: Peak width variation with changes split ratios. Perkin Elmer, Beaconsfield, England (in press). (Application note).

10. Levere RD, Ibraham NG. The bone marrow as a metabolic organ. Ann J Med 73 (1982) 615.

11. Malmgren R. Methodological aspects of studies on the 5-HT uptake mechanism in normal platelets. Acta Pharmacol Toxicol 49 (1981) 277-284.

12. Malmgren $\mathrm{R}$, Åsberg $\mathrm{M}$, Olsson $\mathrm{P}$, Tornling $\mathrm{G}$, 
Unge $G$. Defective serotonin transport mechanism in platelets from endogenously depressed patients. Life Sci 29 (1981) 2649-2658.

13. Malmgren R, Grubbström J, Theorell H, Tornling G, Unge G. Defective serotonin (5-HT) transport mechanism in platelets from patients with endogenous and allergic asthma. Allergy 37 (1982) 29-39.

14. Malmgren R, Olsson P, Tornling G, Unge G. Acetylsalicylic asthma and migraine - A defect in serotonin (5-HT) uptake in platelets. Thromb Res 13 (1978) 1137-1139.

15. Malmgren R, Olsson P, Tornling G, Unge G. The 5-hydroxytryptamine take-up mechanism in normal platelets and platelets from migraine and asthmatic patients. Thromb Res 18 (1980) 733-741.

16. National Board of Occupational Safety and Health. Limit values. Stockholm 1981. (Directions 8).

17. Nilsson A, Oscarsson B, ed. Solvents in the work environment. Swedish Work Environment Fund, Liber, Stockholm 1980.

18. Pletscher A, Laubscher A. Blood platelets as models for neurons: Uses and limitations. J Neural Transm Suppl 17 (1980) 7-16.

19. Robbins SL. Pathological basis of disease. WB Saunders, Philadelphia, PA 1974.

20. Rodbard D. Mathematics of hormone-receptor interactions. In: O'Malley BD, Means AR, ed. Advances in experimental medicine and biology. Volume 26. Plenum Press, New York, NY 1973, pp 289-326.

21. Saunders KJ. Techniques for atmospheric analysis. In:
Albaiges J, ed. Analytical techniques in environmental chemistry. Volume 2. Pergamon Press, Oxford 1982.

22. Savolainen $\mathbf{H}$. Some aspects of the mechanisms by which industrial solvents produce neurotoxical effects. Chem Biol Interact 18 (1977) $1-10$.

23. Sax NJ. Dangerous properties of industrial materials. Fifth edition. Van Nostrand Reynold Co, New York, NY 1975.

24. Schaumburg H, Spencer P. The neurology and neuropathy of the occupational neuropathies. J Occup Med 18 (1976) $739-742$

25. Siggaard-Andersen $O$, Thode $J$, Wandrup $J$. The concentration of free calcium ions in the blood plasma "ionized calcium." Radiometer A/S, Copenhagen 1980. (Application note no A 79).

26. Sneddon JM. Blood platelets as a model for monoamine-containing neurons. In: Kerkut GA, Phillips JW, ed. Progress in neurobiology. Volume 1. Pergamon Press, Oxford 1973, pp 151-192.

27. Stahl MS, Melzer HY. A kinetic and pharmacological analysis of 5-hydroxytryptamine transport by human platelets and platelet storage granules: Comparison with general serotonergic neurons. J Pharmacol Exp Ther 205 (1978) 118-131.

Received for publication: 26 September 1983 